

\section{O INVENTÁRIO DA PAISAGEM DA FOZ DO RIO SÃO FRANCISCO NOS ESTADOS DE ALAGOAS E SERGIPE: UMA EXPERIÊNCIA DE INVESTIGAÇÃO DO PATRIMÔNIO CULTURAL}

\section{Mônica de Medeiros Mongelli}

Arquiteta e Coordenadora no Departamento do Patrimônio Material e Fiscalização - Depam Instituto do Patrimônio Histórico e Artístico Nacional - Iphan, Ministério da Cultura - Governo Federal do Brasil

\section{RESUMO}

Este artigo apresenta uma experiência de trabalho conduzida pelo Instituto do Patrimônio Histórico e Artístico Nacional - IPHAN/ Ministério da Cultura/ Governo Federal do Brasil, através de uma equipe de especialistas contratados, que desenvolveu o Inventário da Paisagem Cultural na Foz do Rio São Francisco, porção territorial que inclui os municípios de Pacatuba, Brejo Grande e Piaçabuçu, nos Estados de Alagoas e Sergipe, região Nordeste do Brasil.

O método de inventário foi oferecido pelo IPHAN e se baseou nas fichas do Sistema Integrado de Conhecimento e Gestão - SICG e em um questionário para entrevistas, com o objetivo de gerar análises e interpretações acerca das referências culturais das comunidades que vivem tradicionalmente na paisagem.

Palavras chave: paisagens culturais, Rio São Francisco, inventário, processos territoriais
Arquitetura vernacular em palafita.llha do Cabaço, Pacatuba/SE. Foto de Mariana Diniz, 2014. Fonte: Acervo IPHAN - "Inventário de conhecimento do Patrimônio Cultural da Foz do Rio São Francisco, nos municípios de Brejo Grande, Pacatuba e Piaçabuçu SE e AL". Empresa contratada: Memória Arquitetura (2014). 
ID_PESQUISAS

\section{RESUMEN}

Este texto presenta una experiencia de trabajo llevado a cabo por el Instituto del Patrimonio Histórico y Artístico Nacional - IPHAN/ Ministerio de Cultura de Brasil, a través de un equipo de especialistas contratados, que realizó el Inventario del Paisaje Cultural en la desembocadura del Río San Francisco, porción territorial que incluye las municipalidades de Pacatuba, Brejo Grande y Piaçabuçu, en las províncias de Alagoas y Sergipe, región Nordeste de Brasil.

El método del inventario fue ofrecido por el IPHAN y se basó en fichas del Sistema Integrado de Conocimiento y Gestión - SICG y en un cuestionario para entrevistas, con el objetivo de generar análisis e interpretaciones acerca de las referencias culturales de los pueblos que viven tradicionalmente en el paisaje.

Palabras clave: paisajes culturales, Río San Francisco, inventario, procesos territoriales.

\section{ABSTRACT}

This paper presents an experience of work carried out by the National Historic and Artistic Heritage Institute - IPHAN / Ministry of Culture of Brazil, through a hired expert staff, who conducted the inventory of the Cultural Landscape of the mouth of the San Francisco River, a territorial portion that includes the municipalities of Pacatuba, Piaçabuçu and Brejo Grande, in the states of Alagoas and Sergipe, Northeast Region of Brazil.

The inventory method was offered by the IPHAN and was based on the forms of the Integrated System of Knowledge and Management - SICG and on a questionnaire for interviews, used in order to generate analysis and interpretations about the cultural references of peoples living traditionally in the landscape.

Keywords: cultural landscapes, San Francisco River, inventory, territorial processes. 


\section{INTRODUÇÃO}

Esse artigo apresenta uma experiência de realização de inventário do patrimônio cultural pelo Instituto do Patrimônio Histórico e Artístico Nacional - IPHAN/ Ministério da Cultura/ Governo Federal do Brasil, com o fim de identificação e reconhecimento da paisagem cultural da Foz do Rio São Francisco, nos Estados de Alagoas e Sergipe.

Trata-se dos resultados de trabalho executado por equipe multidisciplinar contratada pela autarquia no ano de 2014, com base em metodologia de inventário fornecida pelo IPHAN para gerar compreensão sobre a porção territorial da foz do rio, sobre as comunidades locais e seu patrimônio cultural. Essa metodologia consistiu de um roteiro para realização de entrevistas, aliado ao uso de determinadas fichas do Sistema Integrado de Conhecimento e Gestão - SICG.

O trabalho contratado durou seis meses e foi realizado por profissionais de formação em História, Ciências Sociais, Arquitetura e Urbanismo e Geografia, orientados por um grupo gestor no Iphan, constituído por técnicos designados pelos Departamentos: do Patrimônio Material e Fiscalização, do Patrimônio Imaterial; e das Superintendências Estaduais do IPHAN em Sergipe e Alagoas.

A razão de se apresentar esse caso, com ênfase no método utilizado e nos resultados da pesquisa, é por se tratar de um esforço de desenvolvimento de projeto transversal, envolvendo algumas unidades administrativas do Iphan e servidores de formação e lotação distintas. O referido "roteiro para realização de entrevistas", ou um roteiro sintético de questões, foi formulado especificamente para esse trabalho e orientado por membros do grupo integrantes do Departamento do Patrimônio Imaterial, os quais se inspiraram na experiência prática de uso do Inventário Nacional de Referências Culturais - INRC. Já as fichas selecionadas do SICG foram aquelas dos módulos de Conhecimento, de Cadastro e de Gestão, e sua aplicação objetivou o diagnóstico da porção territorial, incluindo aspectos como o da formação histórica, do ordenamento do solo, das dinâmicas naturais e culturais, da incidência dos valores patrimoniais, dos modos de vida das comunidades locais e suas relações estabelecidas com o Rio São Francisco.

Uma vez que a categoria de paisagem cultural pressupõe o conhecimento dos grupos sociais e de seus universos simbólicos, fazia-se necessário que a investigação dos 
pesquisadores contratados se desse essencialmente em campo, com foco nas entrevistas com as comunidades tradicionais. Embora o trabalho de gabinete tenha se mostrado igualmente importante, principalmente para a síntese, interpretação e utilização dos dados coletados, o objetivo primordial do trabalho era mesmo conhecer as comunidades locais, os modos de vida coletivos, aferir a existência de relações de memória e identidade com a paisagem local e regional, bem como atentar para as atividades produtivas, como a pesca artesanal, a carpintaria naval tradicional, a agricultura familiar, o extrativismo, a coleta e o processamento do sururu.

Por outro lado, um pouco do conhecimento preliminar até então disponível sobre a região da foz, o qual permitiu a elaboração objetiva do Termo de Referência para a contratação dos serviços mencionados, deveu-se ao apoio de parceiros interessados na preservação do patrimônio, e em especial ao Sr. Carlos Eduardo Ribeiro Júnior, biólogo e Presidente da Associação Canoa de Tolda - Sociedade Socioambiental do Baixo São Francisco.

A articulação entre o IPHAN e seus parceiros, por sua vez, foi uma construção fomentada a partir da aplicação e difusão de outros dois inventários de varredura precedentes, que abrangeram localidades na calha do Rio São Francisco em cinco Estados da Federação: Minas Gerais, Bahia, Pernambuco, Alagoas e Sergipe. Igualmente baseados no SICG, esses inventários do IPHAN foram realizados nos anos de 2008 a 2010, e objetivaram uma varredura bem geral sobre o patrimônio cultural relacionado ao rio. Tal panorama será relatado no tópico seguinte.

\section{ANTECEDENTES: A POLÍTICA INSTITUCIONAL E OS INVENTÁRIOS DE VARREDURA}

Conforme já mencionado, o projeto de realização do inventário de varredura de localidades na calha do Rio São Francisco remonta ao ano de 2008 e foi defendido pela área central do IPHAN em um contexto em que o corpo dirigente, apoiado pelo Ministério da Cultura, analisava o modo como o patrimônio cultural estava representado no território nacional. Diagnosticou-se que havia distribuição desigual dos bens protegidos entre os Estados da Federação e também que algumas temáticas vinham sendo repetidamente priorizadas na prática preservacionista - tudo isso com base em levantamentos, produção de dados estatísticos, mapas, avaliação de relatórios sobre gestão. Para além desse esforço de 
reflexão sobre a proteção patrimonial estabelecida e sobre a cartografia cultural, estavam sendo considerados estudos recém-publicados e outras bases que apontavam incoerências e distorções em relação ao potencial do patrimônio nacional frente ao que se encontrava tombado e às narrativas privilegiadas na própria ação institucional, problemática essa rebatida também na amostragem de bens classificados como Patrimônio Mundial.

O IPHAN foi criado e definido em 1937, por meio do Decreto-lei ${ }^{\circ} 25 / 1937$; logo em seus primeiros anos e depois décadas de funcionamento, ocorreu o tombamento de significativa quantidade de bens, conforme o ideário da época. Os anos passaram e, na primeira década de 2000 , o retrato do patrimônio material tombado continuava, em alguns aspectos, semelhante ao que se verificava desde o momento fundador da autarquia: com predomínio de bens culturais valorados pelo interesse estético e monumental; com destaque para as construções eruditas e representativas de nossa herança colonizadora ibérica; com inscrições majoritariamente no Livro do Tombo das Belas Artes; e com profusão de bens arquitetônicos e artísticos representativos do período colonial, como igrejas, conventos, fortes e palácios. O desequilíbrio ocorria também quanto à distribuição dos bens no território nacional, pois essas arquiteturas estão concentradas principalmente nas regiões Sudeste, Nordeste, Sul e nas Minas Gerais.

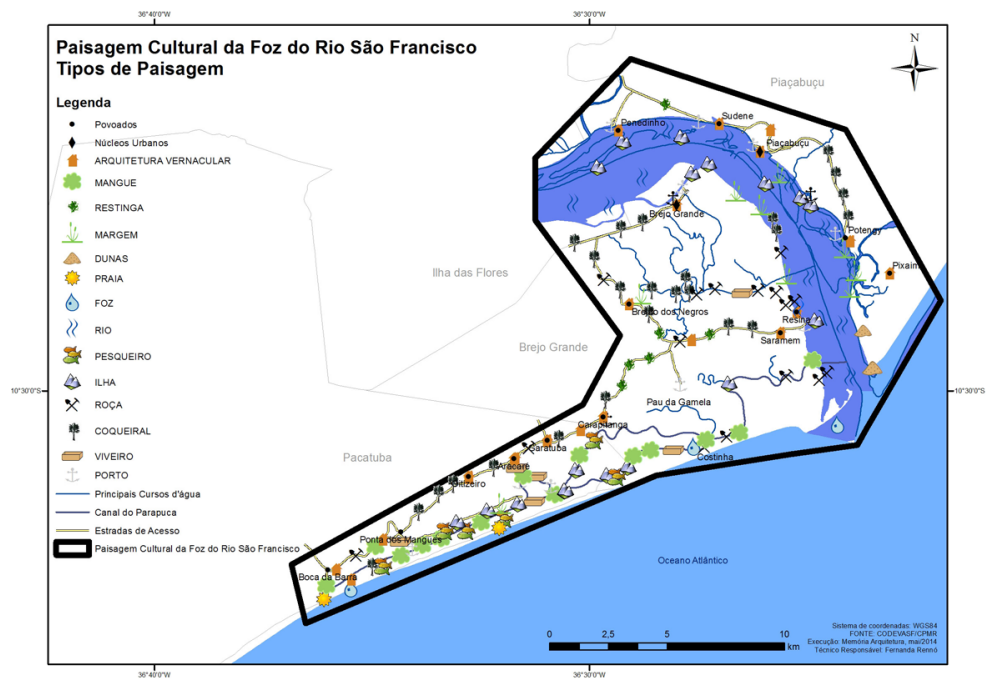


Partindo desse diagnóstico, os objetivos institucionais e os esforços no empreendimento de mudanças estiveram fundados nos ideais de ampliação e atualização do rol de bens protegidos no Brasil; de incorporação da crescente diversificação temática; de se compreender outros significados do patrimônio; de se trabalhar considerando a totalidade dos Estados da Federação e com especial atenção para aquelas regiões com potencial patrimônio cultural ainda não reconhecido e contemplado com ações de acautelamento; de se fortalecer uma possível rede de ação no território; e, finalmente, de se cumprir a missão social institucional contando com o auxílio de parceiros interessados na preservação. Entre os princípios de se trabalhar pelo patrimônio como fator de desenvolvimento estava a compreensão de que sua constituição é dinâmica e de que, em última instância, o patrimônio histórico nada mais é do que a seleção daquilo que deve existir no futuro, assegurado às gerações subsequentes, sob o risco de empobrecimento das culturas e de perda das referências coletivas.

Para fazer frente a essa noção ampliada de patrimônio, a política institucional esteve voltada, entre outros, para o reconhecimento de extensas porções territoriais, para a diversificação da composição dos bens patrimoniais e o fortalecimento de parcerias para as iniciativas de preservação. O Patrimônio Cultural do Rio São Francisco foi um dos temas de estudo, pela importância simbólica do rio e pelo papel que deteve na formação territorial, social e econômica do Brasil. O "Velho Chico", maior rio totalmente brasileiro, serviu de eixo de ocupação do litoral para o interior, e identificá-lo por meio do recém-criado Sistema Integrado de Conhecimento e Gestão - SICG passou a ser estratégico até mesmo para se testarem as novas fichas de inventário. Ou seja, os inventários de varredura permitiram, entre outros, o redirecionamento do conhecimento para os macroprocessos históricos, econômicos, naturais e culturais associados ao rio e vinculados à História do Brasil, e ainda revelaram conjuntos urbanos com arquitetura eclética e vernacular; exemplares relevantes do patrimônio naval; do patrimônio paisagístico; do patrimônio rural; do patrimônio imaterial; e do patrimônio ferroviário.

Informatizado, o sistema SICG e suas fichas de inventário seguem a lógica de se buscar o conhecimento dos bens culturais partindo de informações da escala geral para a individual, ou dos contextos culturais históricos e geográficos até os bens individuais e isolados, os quais são georreferenciados, interrelacionados e adquirem um número especial de cadastramento. 
Acrescente-se que no período de constituição do SICG, e ainda na intenção de aprimoramento dos instrumentos de gestão, formulou-se a Portaria IPHAN nº 127/2009, que estabelece a chancela da Paisagem Cultural Brasileira. $O$ instrumento foi criado com vistas ao acautelamento das paisagens, dinâmicas e mutáveis por definição, e para a salvaguarda das atividades tradicionais ou de valor cultural verificadas no território. Os procedimentos previstos para a chancela implicam a formulação de um pacto entre parceiros para um plano de gestão, incluindo ações a serem realizadas com participação social, na perspectiva da construção continuada das políticas públicas com ênfase nos contextos regionais e locais.

Por fim, após as contratações terem sido realizadas e a conclusão dos inventários de varredura sobre o Rio São Francisco, a estratégia adotada pelo IPHAN para valorização desse rico patrimônio foi a de difundir os resultados dos estudos por meio de apresentações e oficinas de trabalho, buscando estabelecer uma rede de parceiros envolvidos com a temática da preservação. Como consequência, algumas ações conjuntas se desdobraram em certas regiões, estados e municípios.

Na região do Baixo São Francisco, por exemplo, o parceiro Carlos Eduardo Ribeiro Júnior, Presidente da Associação Canoa de Tolda e então Coordenador da Câmara Consultiva Regional do Baixo São Francisco no Comitê de Bacia Hidrográfica do Rio São Francisco - CBHSF/CCRBSF, auxiliou o IPHAN e outros envolvidos especificamente quanto ao conhecimento in loco do território, quanto a questões relacionadas ao patrimônio natural e cultural associado ao rio, e quanto à articulação política regional e local. Foi ele também quem apresentou ao IPHAN, no ano de 2011, um requerimento de tombamento federal da paisagem da foz, apontando uma série de problemas quanto ao gerenciamento do território, denunciando o turismo predatório; a poluição das águas; a extração de petróleo em local impróprio; a criação de viveiros de camarões; a indevida ocupação imobiliária; o progressivo assoreamento do rio; os impactos com a operação das barragens; a diminuição da vazão de água e outros fatores que colocavam em risco progressivo a paisagem da foz e prejudicavam a vida das comunidades tradicionais.

Até que, em maio de 2012, o IPHAN, com o apoio e articulação da equipe da Associação Canoa de Tolda e da Universidade Federal de Alagoas - UFAL, promoveu, na cidade de Penedo, um encontro para discutir o patrimônio natural e cultural do Baixo São Francisco. Inscreveram-se quase setenta participantes, entre palestrantes e convidados, sendo que 
o IPHAN se fez presente com dois conselheiros do Conselho Consultivo; o antigo e o atual Diretor do Depam; os Superintendentes do IPHAN em Sergipe e Alagoas; e cinco representantes do corpo técnico. Em relação às demais instituições, cinco universidades estiveram representadas (UFS, UFAL, USP, UFPE, Faculdade Atlântica), além da Secretaria de Turismo de Piaçabuçu/AL, Secretaria de Meio Ambiente de Piaçabuçu/AL, Instituto Federal de Tecnologia e Ciência de Alagoas - IFAL, Instituto Ambiental Brasil Sustentável - IABS, Companhia de Desenvolvimento do Vale do São Francisco e Parnaíba - Codevasf, Ordem dos Advogados de Sergipe - OAB/SE, UDEMA/AL, Farol da Foz Ecoturismo e CBHSF. Foram apresentadas comunicações e, ao final, abriram-se rodas de discussão sobre o patrimônio natural e cultural do Baixo São Francisco, incluindo medidas que poderiam ser tomadas para o aprofundamento da identificação desse patrimônio. $O$ grupo reunido constatou ser ideal a aplicabilidade do instrumento da chancela da Paisagem Cultural Brasileira para a preservação dos valores culturais daquela porção territorial. E finalizou o Seminário com a produção de um documento intitulado Declaração Sobre a Importância da Preservação da Paisagem Cultural e Natural do Baixo São Francisco, com validação coletiva para o requerimento da chancela.

Nessa mesma oportunidade, os representantes do IPHAN, com o auxílio da equipe da Associação Canoa de Tolda, realizaram uma visita técnica a fim de conhecer e inspecionar as áreas costeiras da foz integrantes do território a ser inventariado e supostamente preservado. O grupo reunido percorreu a ilha de Brejo Grande, em Sergipe; os apicuns do canal da Parapuca, também em Brejo Grande; as barras do sul, zona lagunar onde as comunidades marisqueiras sobrevivem da coleta de massunins, ostras, sururus e taiobas; e o município de Piaçabuçu, em Alagoas.

Esse primeiro reconhecimento in loco da porção territorial facilitou a elaboração do Termo de Referência para a contratação de serviços especializados de inventário da paisagem da foz do São Francisco, conforme se comenta a seguir. 


\section{O INVENTÁRIO ESPECÍFICO DA PAISAGEM DA FOZ}

Como continuidade ao trabalho em curso, no final de 2013, o Departamento do Patrimônio Material e Fiscalização - Depam, com a participação do Departamento do Patrimônio Imaterial - DPI e das Superintendências Estaduais do IPHAN em Sergipe e em Alagoas, contratou o Inventário de conhecimento do patrimônio cultural da foz do Rio São Francisco nos municípios de Brejo Grande/SE, Pacatuba/SE e Piaçabuçu/AL, com vistas a verificar a viabilidade do estabelecimento da Chancela da Paisagem Cultural Brasileira para a porção territorial e, posteriormente, formular o dossiê para o reconhecimento do bem. Desde a concepção do Termo de Referência, as quatro unidades administrativas do IPHAN estiveram envolvidas, tanto na produção do texto quanto na delimitação do objeto e na especificação dos serviços a serem contratados. As localidades municipais pré-definidas foram essas citadas em função dos inventários gerais de varredura, das informações fornecidas pelos parceiros e da visita em campo realizada na ocasião do Seminário em Penedo.

O Inventário SICG somado ao "Roteiro para o Levantamento de Referências Culturais da Paisagem Cultural da Foz do Rio São Francisco" contemplaram as seguintes atividades, organizadas em etapas de entrega:

- Realização de pesquisa histórica, iconográfica, audiovisual e bibliográfica sobre a região do Baixo São Francisco e sobre os três municípios selecionados. O foco da investigação recaiu sobre os valores paisagísticos, buscando-se informações sobre a porção territorial da foz e as comunidades a ela ligadas por relações de vida, trabalho, memória e identidade cultural.

- Produção de mapas temáticos e cartografia interpretativa da incidência e localização dos diversos bens culturais relacionados à foz do Rio São Francisco.

- Relatório sobre a dimensão imaterial do patrimônio associado à paisagem cultural, objetivando aferir relações entre as identidades culturais e a paisagem, as memórias individuais e coletivas, e identificar os fatores de risco de perda do patrimônio, suas fragilidades e as ações possíveis para a salvaguarda dos bens culturais. 


\section{ID_PESQUISAS}

- Setorização das diferentes áreas que compõem o sítio e sua ambiência, por meio da delimitação de uma poligonal para reconhecimento da Paisagem Cultural da Foz do Rio São Francisco.

- Plano de Preservação da Paisagem Cultural: discriminação das diversas unidades de paisagem encontradas na área pré-definida pelo IPHAN; determinação das potencialidades e fragilidades do ponto de vista ambiental, paisagístico e socioeconômico; cartografia contendo as subdivisões das unidades de paisagem; indicação do potencial de novas parcerias; proposição de medidas de atuação visando a mitigar e compensar os impactos culturais e ambientais detectados, ou a efetivar as potencialidades encontradas; indicações para revisão de planejamento territorial e urbano; proposição de ações relativas ao patrimônio imaterial refletindo questões de memória e identificação com a paisagem cultural, conforme verificado a partir das entrevistas; proposição de ações relativas ao patrimônio material visando a sua preservação e valorização.

Para esse trabalho contratado, a primeira iniciativa foi a realização de uma reunião inicial de capacitação técnica com representantes do IPHAN e da empresa vencedora da licitação para afinar os conceitos básicos, os objetivos e o método para o desenvolvimento do projeto.

Especificamente, foram tratados os seguintes pontos:

- Nivelamento conceitual sobre paisagem cultural

- Análise do plano de trabalho

- Abordagem dos focos da pesquisa (proposta de roteiro)

- Levantamento de atores

- Agenda de trabalho

$\mathrm{Na}$ ocasião, ainda, destacaram-se questões essenciais, como:

- Que as entrevistas fossem conduzidas pelo cientista social;

- Que houvesse previsão de tempo suficiente para o trabalho de campo, envolvendo o reconhecimento do local e a realização de entrevistas; 
- Que se evitasse mudança de integrantes da equipe durante o desenvolvimento do trabalho;

- A necessidade de observação da natureza interdisciplinar do projeto e a necessidade de promoção de constante diálogo entre os membros da equipe;

- Que se precisasse a constituição do objeto da pesquisa e se apresentassem as hipóteses a serem investigadas, considerando-se os vários inventários e trabalhos até então produzidos e disponibilizados pelo IPHAN.

Quanto ao roteiro para realização de entrevistas, foi esclarecido tratar-se apenas de um universo de questões para o entrevistador, que, na qualidade de cientista social, teria todo o arcabouço científico-metodológico para definição da maneira exata de trabalhar. Assim, foi explicitado que:

- O roteiro nunca deveria ser submetido à resposta autônoma dos entrevistados, sendo necessária a mediação do profissional acima descrito para decodificar as respostas a partir de leituras constituídas sob a ótica do patrimônio.

- O universo de aplicação do roteiro deveria ser previamente pensado, de modo a contemplar a multiplicidade de atores sociais necessários ao entendimento dos elementos culturais que se desejava mapear. Era preciso envolver um número de sujeitos sociais correspondente às diferentes formas de vivenciar a paisagem em estudo.

Finalmente, o denominado "Roteiro para o Levantamento de Referências Culturais da Paisagem Cultural da Foz do Rio São Francisco" contemplava: a identificação do informante; sua história pessoal no território; questões sobre a percepção da paisagem; sobre as referências culturais; sobre a preservação da paisagem; e sistematização das informações.

Para ilustrar, desdobramos as questões quanto à "História pessoal no território":

- Há quanto tempo você mora no local?

- A família reside no local?

- Quando e por que você e sua família vieram para o local?

- Como é viver no local? 


\section{ID_PESQUISAS}

- O que mais gosta da vida no local?

- Quais as principais dificuldades da vida no local?

- O que você mudaria?

Quanto à "Percepção da paisagem":

- Quais elementos da paisagem você destaca e por quê?

- Quais mudanças na paisagem você tem percebido ao longo do tempo e quais fatores têm causado essas mudanças?

- Qual a importância do rio para você e para a região?

- Como as pessoas se relacionam com o rio? (Quais as práticas de lazer, de subsistência, de religiosidade, de trabalho e de transporte que utilizam o contexto do rio como o principal meio material e/ou simbólico de existência?).

\section{Quanto às "Referências Culturais":}

- Quais as festas, eventos, comemorações que você conhece ou de que participa na região?

- Qual a época delas?

- Quais as músicas, danças, encenações que você considera típicas da região? Quando são realizadas?

- Existem grupos culturais na região?

- Você acha que há um jeito de falar próprio da região? Como é esse jeito?

- Quais as histórias sobre o rio/ a paisagem? (Considerando narrativas de eventos históricos e mitos ou lendas).

- Quais as atividades/ profissões/ meios de subsistência mais comuns na região? (As pessoas vivem de quê? Incluindo programas governamentais de assistência).

- Como as pessoas se utilizam dos recursos naturais? (Água, vegetação, demais matérias primas. Perguntar sobre ofícios tradicionais, dando exemplos: barqueiros, benzedores, raizeiras...). 
- Quais as principais comidas? Elas têm preparos ou receitas especiais?

- Quais os lugares mais importantes da região e por quê? (Entre os lugares construídos, os paisagísticos, os sagrados).

- Existem comunidades tradicionais - indígenas, quilombolas?

- Cite os principais grupos culturais e seus detentores existentes no município.

Quanto à "Preservação da Paisagem":

- Você acha que as pessoas cuidam ou se preocupam com o rio/ a paisagem?

- O que mais destrói ou causa problemas ao rio/ paisagem?

- Você gostaria de fazer alguma coisa para preservar o rio/ paisagem? O que acha que poderia ser feito?

- Você conhece órgãos públicos ou instituições que trabalham com a preservação do rio/ paisagem?

Sendo esses os principais tópicos do roteiro de entrevistas, passemos à descrição detalhada dos produtos entregues pela contratada.

\section{RESULTADOS DO INVENTÁRIO DA PAISAGEM DA FOZ}

Conforme requisitado no Termo de Referência, e na forma dos quatro produtos apresentados, esse inventário trouxe como resultados:

\section{Produto 1 - Estudo do objeto e Plano de Trabalho}

O produto serviu para detalhamento, pela contratada, do método aplicado de pesquisa, da logística referente às visitas de campo, da divisão de tarefas entre as equipes de trabalho, da revisão bibliográfica e outros.

Nos estudos preliminares, a contratada escreveu: a fim de compreender os valores que são atribuídos à paisagem cultural da região da Foz do Rio São Francisco, a equipe envolvida no 


\section{ID_PESQUISAS}

trabalho dedicou-se à leitura de dossiês e inventários resultantes da atuação do IPHAN ao longo de diversos anos, em especial o Inventário Nacional de Referências Culturais - INRC da região ribeirinha sergipana do Baixo São Francisco, que realizou um estudo dos bens culturais em diversos municípios, dentre os quais Brejo Grande/SE. Embora não enfocasse os municípios de Pacatuba/SE e Piaçabuçu/AL, esse inventário forneceu elementos suficientes para traçar um panorama sobre as práticas que se desenvolvem naquela paisagem cultural. A leitura desses estudos e de outros artigos apresentou um panorama da atuação do IPHAN no que tange à chancela da paisagem cultural e das discussões sobre o patrimônio cultural na região, fornecendo, assim, subsídios para a elaboração de uma bibliografia preliminar que abordasse o Baixo São Francisco, em especial a região da foz, compreendida pelos municípios de Brejo Grande/SE, Pacatuba/SE e Piaçabuçu/AL.

E escreveu, ainda, a respeito da leitura realizada de obras clássicas da historiografia sergipana, comprometendo-se a buscar o incremento de fontes bibliográficas referentes a Alagoas.

A contratada apresentou, então, listagem das instituições com acervos de potencial interesse para a pesquisa, "identificados previamente por meio de referências de outras obras e pela internet".

E optou por realizar uma "Viagem Precursora" para reconhecimento do território; das instituições relevantes para o desenvolvimento da pesquisa; das lideranças comunitárias e definição das pessoas a serem entrevistadas. Sobre isso, esclareceu-nos a contratada a respeito da estratégia utilizada: como parte da metodologia adotada, durante a viagem precursora e para cada localidade, foi solicitada aos gestores públicos e aos moradores contatados a indicação de pessoas chave para a realização de entrevistas (...). Inicialmente, buscou-se a diversidade de agentes de forma a subsidiar a verticalização ao longo da pesquisa, a ser atingida com os demais campos. (...) Listaram-se, por conseguinte, os seguintes grupos sociais que, devido à suas atividades produtivas, políticas, culturais e comunitárias, foram considerados agentes sociais significativos no processo de atribuição de valor cultural à paisagem da Foz do São Francisco: gestores públicos; lideranças comunitárias; pessoas ligadas às principais atividades econômicas de cada localidade; antigos moradores das comunidades; e agentes envolvidos com manifestações culturais. 
Detalhou-nos a contratada:

- A opção pela abordagem e realização de entrevistas com os gestores públicos pretendeu identificar ações políticas, medidas urbanísticas, estratégias de uso ou proteção da porção territorial, e significações institucionais voltadas para a Paisagem Cultural da Foz do Rio São Francisco. (...) Os gestores públicos são personagens estratégicos tanto no que se refere à elaboração de um plano compartilhado de gestão, como ao monitoramento das ações em nível local.

- As lideranças comunitárias foram citadas como agentes a serem abordados em campo por se tratarem de mobilizadores de ações que, não raro, se voltam para lutas em favor dos interesses de grupos sociais que vivem e desenvolvem suas atividades culturais, sociais e produtivas a partir da Paisagem Cultural da Foz do Rio São Francisco. As lideranças comunitárias buscam articular o desenvolvimento dos componentes que sustentam as comunidades em seus diversos aspectos: econômico, social, ambiental, cultural, dentre outros. (...).

- (...) as entrevistas com representantes das atividades econômicas buscarão (...) relacionar as alterações ambientais que impactaram as atividades econômicas ao longo do tempo e as estratégias desses grupos para a continuidade de seus trabalhos (...). No caso dos carpinteiros navais, busca-se identificar como essa forma tradicional de produção de embarcações pode ter sido modificada diante das ações que alteraram significativamente as características hídricas do rio, incluindo a utilização de seu potencial energético, a construção das barragens, a irrigação, o processo de transposição, e tudo aquilo que impactou outras atividades que dependam das águas do São Francisco.

- As entrevistas com antigos moradores e com pessoas envolvidas com as manifestações culturais que ocorrem nas comunidades investigadas pretendem identificar aspectos históricos e simbólicos relacionados às povoações dessa região. (...) Os moradores antigos foram interpretados como informantes sobre a paisagem por conta de suas memórias, considerando que as lembranças são significações que se revelam tendo o tempo como articulador e organizador das apreciações. (...) As histórias de vida desses moradores guardam percepções sobre a paisagem que são individuais, mas também coletivas.

Para execução da pesquisa conforme definida pela contratada no Plano de Trabalho, foram previstas outras três etapas de visita em campo. 
Produto 2 - Levantamento de dados em campo e preenchimento das fichas SICG dos módulos de Conhecimento e Cadastro. Relatório síntese interpretativo a partir da elaboração de entrevistas.

Esse produto trouxe informações coletadas a partir das entrevistas baseadas no "Roteiro para o Levantamento de Referências Culturais da Paisagem Cultural da Foz do Rio São Francisco". Foi uma das etapas mais importantes do trabalho, pois significou a interlocução direta com as comunidades ribeirinhas e a possibilidade de entender suas percepções sobre a vida local, bem como observar relações entre as identidades culturais e o rio.

Nesse sentido, a contratada teve facilidade em perceber fortes vínculos afetivos, de memória e de pertencimento entre os habitantes locais e a paisagem, conforme exemplifica a redação abaixo:

O Rio São Francisco é o principal atributo no processo de significação da paisagem cultural, como observado nas entrevistas. A interpretação da paisagem, na maioria das narrativas recolhidas, toma as vivências pessoais e coletivas com o rio e seus cenários para descrever e revelar a afetividade que liga as pessoas ao espaço que habitam. Assim, o rio é colocado como o principal cenário das experiências vividas e rememoradas (vivência/memória), ainda que as águas não sejam o palco principal dos acontecimentos na vida das pessoas. É o caso dos moradores de Pixaim, que se referem ao rio e ao mar, às águas, como contraponto da paisagem árida das dunas, mas mantêm a interpretação das águas como elemento primordial de existência da comunidade, seja pela pesca no mar ou pelas antigas plantações de arroz nos brejos de água doce. A percepção da paisagem liga-se, nesse sentido, diretamente ao rio, o qual é visto como principal espaço social para as populações da região. A afetividade foi, portanto, o principal aspecto na percepção da paisagem a partir do rio (...).

Não apenas a interpretação das entrevistas, mas também os próprios trechos das falas dos entrevistados ilustram o que foi observado pela contratada, como:

O Rio São Francisco representa não só para mim como para todos, tudo que a gente tem. (Trecho da fala de José Henrique Teles dos Santos, pescador e antigo morador do Povoado de Cabeço, atual morador de Brejo Grande/SE). 
Ou conforme se manifestou José Geraldo Santos, mestre carpinteiro naval do município de Sudene (Mandim): O rio é tudo para mim, tudo que eu tenho eu agradeço ao rio. O rio é um pai, uma mãe [...].

E ainda, conforme Cícero Cruz da Silva, carpinteiro naval reconhecido como Mestre Ferrâncio, de Piaçabuçu/AL: O Rio São Francisco faz parte da minha vida, é vida, é um pedacinho de mim. O Rio São Francisco para nós é a empresa maior do nordeste [...]. Pra mim [o Rio São Francisco] é como se fossem essas veias [aponta para as veias do braço]. Eu não sei porque, no nosso país, os governantes fazem tanta coisa que destrói esse rio. [...] cada dia que passa a gente vê esse rio morrendo como se fosse uma pessoa que estivesse numa cama agonizando, como se você não tivesse recurso para dar. [...] Antes ele desaguava no mar com tanta força que fazia até medo a gente estar perto. Hoje já não tem mais força, já vi um banco de areia fechando a foz. [...] E agora vai ter mais um desvio. [...] E o nordestino vai viver de quê? [Dirigindo-se às entrevistadoras] Não dá não para vocês fazerem alguma coisa?.

Para além desse Relatório interpretativo, o Produto 2 trouxe ainda as fichas SICG preenchidas dos módulos de Conhecimento e de Cadastro. A ficha M101 - Contextualização Geral referese à coleta e organização de informações em recorte territorial ampliado, como é o caso do Baixo São Francisco, podendo abranger vários municípios. Nessa escala de trabalho, a investigação recaiu sobre temas como a navegação, a arqueologia subaquática, a economia e as trocas comerciais, a produção agrícola, os efeitos dos empreendimentos no rio etc. Já a ficha M102 - Contexto Imediato permite a identificação de localidades municipais, sítios e povoados, mostrando-se adequada para o aprofundamento daquela contextualização inicial obtida por meio da ficha M0101. Foram buscadas informações sobre os povoados de Brejão dos Pretos, Cabeço, Saramén, Resina, Capivara, Carapitanga e Terra Vermelha - em Brejo Grande/SE; Garatuba, Oitizeiro, Boca da Barra, Funil e Ponta dos Mangues - em Pacatuba/ SE; Potengi, Pixaim, Ilha do Gondim e Ilha do Alecrim - em Piaçabuçu/AL.

Quanto às fichas SICG do módulo de Cadastro, elas foram formuladas para descrição e análise de bens individuais relevantes por si mesmos ou dentro de um conjunto. A opção da contratada foi identificar bens representativos associados às práticas e manifestações estudadas na Paisagem Cultural da Foz do São Francisco. Foram selecionados para cadastramento os bens materiais: farol do Cabeço; uma casa de farinha; uma canoa taparica; uma canoa de tolda; uma canoa de corrida; uma casa de taipa; uma casa de palha. 
Além desses, foram elencados outros bens, dessa vez, de natureza imaterial:

- Arquitetura vernacular praieira (modo de fazer);

Conforme a contratada, a arquitetura vernacular praieira - constituída por elementos como construções de taipa, de folhas de coqueiro e de madeira e lama do mangue, dentre outros materiais - é resultante de uma interação com o meio ambiente e da incorporação de saberes e práticas culturais. Essa forma de construir está presente na paisagem da região da foz do Rio São Francisco, estabelecendo um diálogo com o entorno imediato. (...) A utilização desse tipo de técnica construtiva remonta às práticas antigas da região e também foi constatada a partir da análise de fontes histórias (...). Constitui-se em uma prática ligada às experiências e conhecimentos empíricos da comunidade, que utiliza em sua construção recursos e matérias primas existentes na região, bem como se baseia em conhecimentos adquiridos ao longo de gerações. É nesse tipo de habitação que residem os moradores de Pixaim, povoado localizado em meio à formação de dunas móveis em Piaçabuçu.

- Artesanato em palha de ouricouri e palha de taboa (modo de fazer);

Sobre esse tipo de artesanato, a contratada escreveu: Para além da palha do coqueiro, a utilização de duas outras plantas locais foi observada: a palha do ouricuri e a palha da taboa (Typha domingensis), espécie vegetal hidrófita, típica de brejos, manguezais, várzeas. Pelas características de sua fibra, ela é muito utilizada na fabricação de artesanato. (...) O ouricuri também é matéria prima utilizada pelas artesãs da Marituba - povoado de Piaçabuçu - para a produção de um artesanato que inclui peças como bolsas e cestas (...).

- Carpintaria naval (ofício);

Ainda conforme pesquisa da equipe, muitas práticas e manifestações culturais usadas pelas comunidades para interagir com o rio estão ligadas à navegação e ao universo das embarcações. $A$ própria paisagem dos povoados e localidades na Foz do Rio São Francisco é fortemente marcada pela presença desses meios de transporte fluviais. $\mathrm{E}$ também: o ofício de mestre carpinteiro naval possui valor cultural e está intimamente relacionado à Paisagem Cultural da Foz do Rio São Francisco. (...) Tendo em vista as informações prestadas pelos mestres carpinteiros e as observações realizadas durante a pesquisa de campo, foi possível perceber que esse construtor chefe costuma ter na bagagem um grande período de experiência na arte de fabricação de embarcações e a gozar de reconhecimento junto aos demais envolvidos com essa prática laboral e à própria comunidade.

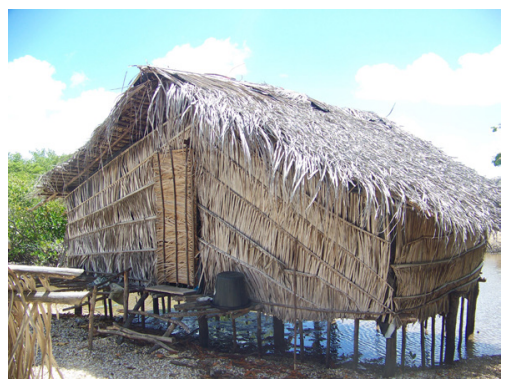

Arquitetura vernacular em palafita. Ilha do Cabaço, Pacatuba/SE. Foto de Mariana Diniz, 2014. Fonte: Acervo IPHAN - "Inventário de conhecimento do Patrimônio Cultural da Foz do Rio São Francisco, nos municípios de Brejo Grande, Pacatuba e Piaçabuçu SE e AL". Empresa contratada: Memória Arquitetura (2014). 
- Corrida de canoas (forma de expressão);

Sobre as corridas de canoas, a contratada nos revelou: constituem-se em eventos tradicionais aguardados por diversas comunidades da Foz do Rio São Francisco e mesmo de toda a região do Baixo Franciscano. A partir das fontes levantadas, não é possível precisar quando - e como - surgiram esses eventos que incorporam muitos dos saberes e práticas culturais locais e que dialogam tão intimamente com a paisagem. Mas é possível afirmar que a própria natureza das atividades de pesca e de navegação desenvolvidas na região exigia dos responsáveis pela condução das embarcações o domínio das técnicas de navegação aliado a apurados conhecimentos do local e dos elementos climáticos da região, tais como o vento e a correnteza. Nesse sentido, cotidianamente - e mesmo de forma lúdica - os pescadores e tripulantes acabavam pondo à prova a qualidade de suas canoas e, principalmente, suas habilidades na condução de tais embarcações, vencendo a aposta a que fosse a mais veloz. Essas disputas eram também uma diversão e uma forma de estreitar laços sociais a partir de uma atividade que eles desempenhavam com destreza cotidianamente: a navegação. Nesse sentido, as corridas de canoas podem ser entendidas como manifestações culturais associadas a outras práticas, tais como a navegação, a carpintaria naval e a própria atividade pesqueira, que servem para estreitar os vínculos sócio-afetivos com a comunidade local.

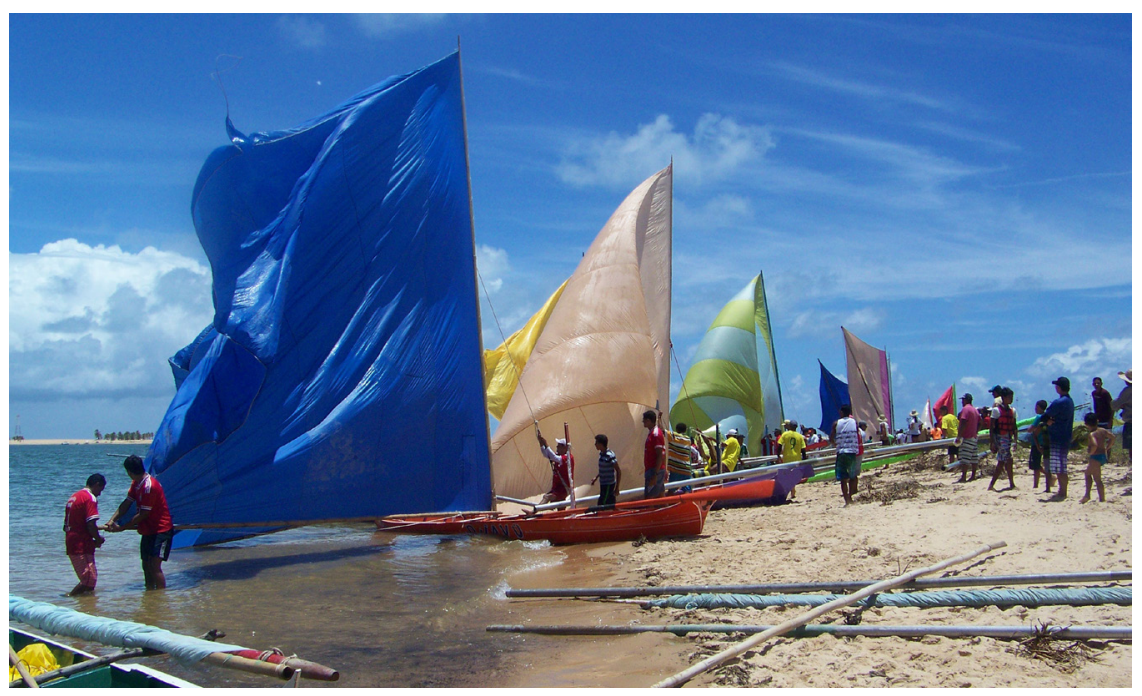
Diniz, 2014 Fonte: Acervo IPHAN - "Inventário de conhecimento do Patrimônio Cultural da Foz do Rio São Francisco, nos municípios de Brejo Grande Pacatuba e Piaçabuçu - SE e AL". Empresa contratada: Memória Arquitetura (2014) 
- Culinária (modo de fazer);

A culinária das várias localidades da região da foz do Rio São Francisco incorporou muitas das matérias primas e dos recursos existentes na região, tais como peixes, crustáceos e frutos do mar. Esse modo de fazer também foi influenciado por elementos da cultura alimentar nordestina. Nos povoados e nos distritos sede dos três municípios pesquisados foi identificada a presença de uma culinária típica que congrega tais ingredientes. Esse modo de fazer, pela sua natureza, envolve um grupo de praticantes bastante amplo, se desenvolvendo tanto no âmbito doméstico como para fins comerciais.

- Cultura do coco (modo de fazer/ofício);

A presença de coqueirais é bastante recorrente nas paisagens da região da foz do Rio São Francisco. Embora essa formação vegetal não seja nativa da região, os coqueiros constituem-se em elementos marcantes da paisagem de diversos trechos dessa porção territorial. Sua cultura é amplamente difundida em localidades dos três municípios, havendo significativa quantidade de pequenos produtores que se dedicam à sua exploração e comercialização.

Embora os cocos produzidos sejam destinados majoritariamente a outros mercados, parte dessa produção é consumida internamente na culinária local, sendo usado no preparo de peixes ou das famosas cocadas produzidas pela 'Associação de Doceiras e Artesãs de Saramém'.

(...) Os instrumentos utilizados pelo catador de coco são semelhantes em toda a região onde há incidência dessa cultura: a peia, o facão - que geralmente fica preso à cintura pela bainha de couro - e um recipiente com uma substância utilizada para afastar marimbondos.

- Festa de Bom Jesus dos Navegantes (celebração);

Sobre essa celebração, a contratada apontou valores culturais e, ao mesmo tempo, fragilidades: a Festa de Bom Jesus dos Navegantes é recriada todos os anos em Brejo Grande e Piaçabuçu. No entanto, nota-se uma tendência de que os eventos relacionados à festa - os shows, barraquinhas e parques - promovidos ou apoiados pela Prefeitura Municipal ganhem maior destaque do que propriamente os ritos de devoção.

(...) A corrida de embarcações é um dos eventos ligados à Festa de Bom Jesus dos Navegantes, celebração que mobiliza a comunidade local anualmente. Pode-se afirmar que a realização desse evento antes da procissão fluvial de Bom Jesus dos Navegantes estabelece uma conexão entre esses dois contextos rituais, congregando valores religiosos, saberes relacionados à construção dessas canoas e atividade de navegação naquela região.

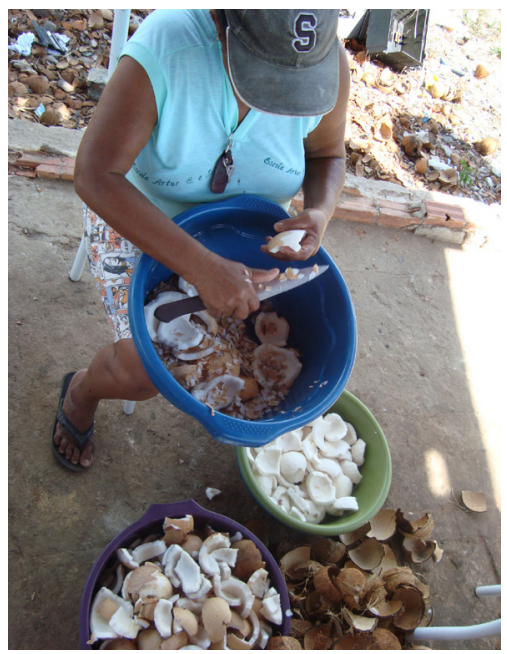

Produção de cocada. Associação das Doceiras de Brejo Grande/SE. Foto de Mônica Mongelli, 2012

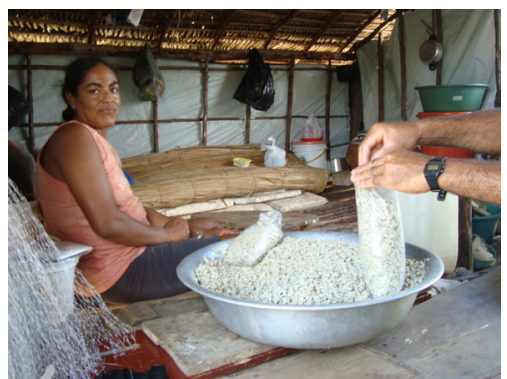

Coleta de Massunim. Pacatuba/SE. Foto de Mônica Mongelli, 2012 
- Pesca Artesanal (modo de fazer/ofício)

Sobre o ofício do pescador, a contratada apontou: é um dos que está mais diretamente conectado à dinâmica dessa paisagem, uma vez que o rio e outros ambientes aquáticos - tais como lagoas e até mesmo o mar - são, por excelência, o espaço onde ele atua. Portanto, algumas modalidades de pesca artesanal e de atividades pesqueiras contribuem para a percepção cultural da paisagem da foz.

(...) Ao longo do tempo, a pescaria artesanal continuou significativa na economia local, de modo que a atividade permanece empregando e mobilizando - de forma direta ou indireta - grande parte da comunidade ribeirinha.

Alguns pescadores artesanais tendem a pescar em uma mesma região em virtude dos recursos pesqueiros ali existentes, de costumes ou outros fatores. Esse aspecto acaba fazendo com que o pescador atribua valores distintos a determinadas paisagens. Ao longo do tempo, os pescadores artesanais adquiriram amplos conhecimentos sobre os elementos da paisagem e sobre as formas de transformá-la (...).



Festa de Bom Jesus dos Navegantes. Ilha das Flores, Brejo Grande/SE. Foto de Mariana Diniz, 2014. Fonte: Acervo IPHAN - "Inventário de conhecimento do Patrimônio Cultural da Foz do Rio São Francisco, nos municípios de Brejo Grande, Pacatuba e Piaçabuçu SE e AL". Empresa contratada: Memória Arquitetura (2014). 
Assim, o que a contratada nos mostrou como conclusão desse Produto 2 foi uma profusão de valores culturais concentrados na Paisagem da Foz do Rio São Francisco - ainda que parte deles não seja específica ou exclusiva do local, dado que representam traços gerais das culturas nordestina e brasileira. Também não há significativo quantitativo de bens materiais passíveis de receberem proposta de proteção patrimonial individual. Porém, há, sim, tradições enraizadas entre as comunidades ribeirinhas e o rio, bem como laços afetivos e de pertencimento entre os grupos sociais e a paisagem local - esta com valor estético e monumental, por seus atributos naturais, ambientais e ecológicos. Além desses valores paisagísticos evidentes, podemos inferir que o espírito do lugar reside também no poder simbólico do rio e na indissociabilidade entre ele e os modos de vida tradicionais estabelecidos no local. Há profundo conhecimento coletivo sobre as dinâmicas do meio e também uma relação sustentável estabelecida entre as comunidades ribeirinhas e o Rio São Francisco. Aí, acreditamos, residiriam os principais fundamentos para a declaração da porção territorial como "Paisagem Cultural Brasileira".

\section{Produto 3 - Relatório sobre legislação incidente na porção territorial da Foz do Rio São Francisco e preenchimento das fichas SICG do módulo de Gestão}

Em continuidade à leitura do território e à identificação dos valores culturais da paisagem da foz, essa etapa previu o tratamento e a qualificação das análises produzidas nas duas etapas anteriores, buscando precisão no diagnóstico, delimitação da porção territorial a ser acautelada e subsídios para um plano de gestão.

Foram utilizadas as fichas SICG do Módulo de Gestão M201 - Pré-Setorização com o objetivo de conduzir à delimitação da porção territorial; à identificação de áreas diferenciadas que a integram; à sua subdivisão em setores; e à concepção de diretrizes gerais de gestão. Esse exercício preliminar foi detalhado por meio da ficha M202 - Caracterização dos Setores, na qual houve uma aproximação escalar da porção territorial delimitada e se descreveu o que está contido em cada setor ou unidade de paisagem. Isso envolve identificar, a cada pequena porção do território, quais seus principais atributos, os fatores de risco, as potencialidades, pressões e demandas, culminando em diretrizes de planejamento 
estratégico. Ou seja, trata-se de procedimento técnico da ciência de planejamento territorial e urbano com vistas à construção de propostas que aliem desenvolvimento à preservação do patrimônio cultural.

Na prática, o preenchimento dessas fichas por parte da contratada levou à Pré-Setorização da porção territorial, observando-se como classificar aquela paisagem e estabelecendo critérios para a diferenciação entre as áreas. Uma primeira diferenciação possível foi entre ambientes mais próximos do "natural" e áreas com agenciamento humano mais evidente, ainda que estivesse claro o fato de toda a porção territorial ter sido historicamente afetada pelos efeitos das interferências e impactos no curso do Rio São Francisco. Mesmo diante dessa observação, foi possível distinguir em campo aquelas subáreas representativas do lado mais nativo da paisagem e, em contraposição, outras partes mais domesticadas, havendo uma gradação entre os dois pólos.

Os demais critérios encontrados para a Pré-Setorização da região foram decorrentes de: fatores históricos, fatores físicos - hidrografia, solo, vegetação - uso do solo, usos socioeconômicos, urbanidade, incidência de bens protegidos e de interesse de preservação, unidades de conservação, eixos visuais, prospecção local, patrimônio imaterial, apropriação e reconhecimento das unidades de paisagem pelos atores locais.

Esse último ponto mostrou-se importante: conforme relato da contratada, por meio do recolhimento de narrativas orais dos moradores ribeirinhos, utilizando-se a metodologia qualitativa e a técnica de entrevistas abertas semiestruturadas, foram alcançados valores e significações que atribuem o sentido de paisagens culturais aos setores (...).

(...) A análise sistemática das narrativas orais apontou para os atributos estético, histórico, econômico, afetivo e ambiental como os principais elementos acionados no processo de valoração das paisagens. $O$ aspecto comum que interligou os setores paisagísticos a partir das entrevistas foi o elemento água, seja do mar, do rio ou o encontro das duas. Em todas as paisagens as águas foram mencionadas como atributo de fartura, de construção e modificação da paisagem e de ocupação e uso do território.

Corroborou-se, portanto, a hipótese inicialmente exposta no Plano de Trabalho, tornando-se verificável que as populações da foz do Rio São Francisco mantêm laços de pertencimento e de identidade com as paisagens culturais ali identificadas, com essas paisagens 


\section{ID_PESQUISAS}

apresentando-se íntegras e bem demarcadas nas memórias e referências afetivas das sociedades ali instaladas. Assim, justifica-se tomar cada um desses setores como paisagens culturais constantes, em um desenho mais amplo, do contexto que forma a Paisagem Cultural da Foz do Rio São Francisco.

Foram pré-definidos seis setores, que muito têm a ver com a geografia física da porção territorial, a saber:

- Setor Azul - O Estuário do Rio São Francisco;

- Setor Verde - O Canal do Parapuca;

- Setor Amarelo - As Dunas;

- Setor Marrom - A Barra;

- Setor Vermelho - As Roças;

- Setor Cinza - O Urbano.

Em breves palavras, o primeiro se relaciona com o uso e dinâmica das águas; o segundo engloba os manguezais e usos que se fazem dele (inclusive predatórios); o terceiro diz respeito às dunas, ponto final para onde se dirige a visitação turística proveniente de vários roteiros; o quarto é uma formação geológica que ocorre nas desembocaduras de canais, estuários e outros cursos de água, com profunda influência do fenômeno de encontro do rio com o mar; o quinto setor contém as propriedades rurais típicas com agricultura de base familiar, sendo também onde se situam as comunidades quilombolas; e o último caracterizase pela presença diferenciada dos núcleos urbanos dos distritos sede dos municípios de Brejo Grande/SE e de Piaçabuçu/AL.

Para cada setor analisado, foram dadas as premissas gerais sobre planos e medidas necessárias à preservação do bem, considerando-se também a perspectiva continuada da construção da política pública, de modo integrado.

Para formular essas propostas, a contratada produziu relatório analítico sobre a legislação no território e sobre como se dá atualmente a gestão da porção territorial pelos vários agentes, da iniciativa pública, privada e sociedade civil. 

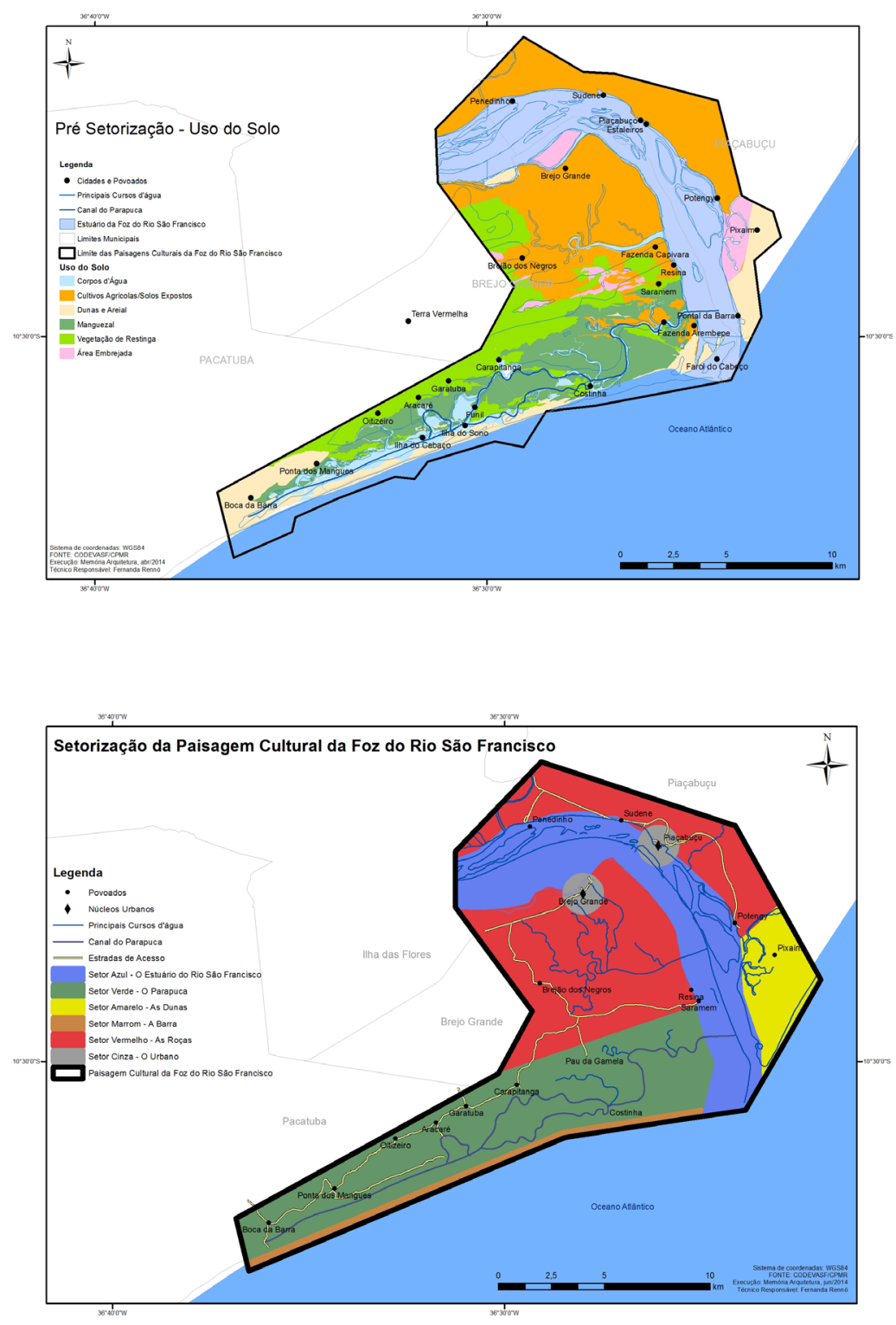
Sobre isso, esclareceu-nos a contratada: "no presente relatório foram colacionados os principais diplomas legais, de competência da União e de cada Estado e Município envolvido, pertinentes para o desenvolvimento de políticas públicas relacionadas ao patrimônio cultural, ao meio ambiente, ao turismo e ao ordenamento do solo urbano. Também foram identificados, especificamente, normativas que recaem sobre territórios quilombolas, áreas rurais e unidades de conservação, além de informações sobre a gestão das águas fluviais e da porção marítima, e da legislação sobre atividades náuticas e de pesca, assim como são mencionados documentos oficiais de maior importância para a gestão da região, tais como programas governamentais, planos de ação e projetos previstos ou em execução".

"Diante de uma perspectiva de planejamento integrado do território da Foz do Rio São Francisco, foi realizado o arrolamento da legislação e de documentos de referência por seara de atuação. $O$ destaque foi dado aos dispositivos diretamente incidentes sobre a área de estudo, além da consulta a diversos documentos oficiais, como plano de manejo, programas de gerenciamento, de fomento, entre outros. Este relatório permitiu, ainda, identificar as diversas instâncias de governança como potenciais entidades para futura proposta de pactuação".

Assim, a contratada analisou: a legislação ambiental incidente, incluindo as normas de proteção para a vegetação nativa; os estudos e Planos de Gerenciamento Costeiro; as Unidades de Conservação estabelecidas, e seus respectivos Planos de Manejo; os Planos de Recursos Hídricos; os dispositivos legais para as terras quilombolas; as legislações turísticas; os fundos e instrumentos de fomento; e outros. Isso foi feito para complementar o conhecimento sobre a porção territorial, os possíveis parceiros, e para que os instrumentos de acautelamento do patrimônio cultural não contradigam demais dispositivos legais vigentes ou em elaboração.

Por fim, a contratada elaborou uma tabela contendo "síntese da principal legislação vigente e aplicada (incidente), bem como os respectivos órgãos competentes e atributos relacionados ao território delimitado como Paisagem Cultural da Foz do Rio São Francisco".

Dessa investigação decorreram recomendações para a preservação da paisagem auxiliando um futuro processo de pactuação institucional. 
Produto 4 - Relatório síntese contendo subsídios para o Plano de Preservação da Paisagem Cultural da Foz do Rio São Francisco. Apontamentos, recomendações e listagem de medidas a serem tomadas entre os pactuantes.

Esse produto serviu para o refinamento, aprofundamento e complementação dos produtos anteriores. Com base no conjunto de fichas SICG elaboradas, no relatório interpretativo das entrevistas e no relatório sobre estudos da legislação incidente, coube à contratada formular proposta de dossiê para a Paisagem Cultural da Foz do Rio São Francisco, incluindo subsídios para um Plano de Preservação.

Além disso, nessa etapa, foi previsto um novo levantamento em campo, incluindo realização de encontros com atores locais, ou grupos focais, com direcionamento da reflexão tanto para apresentação dos achados da pesquisa quanto para discussão sobre os conflitos verificados na porção territorial.

Uma recomendação do Iphan à contratada foi não gerar expectativas entre os grupos sociais quanto ao estabelecimento da chancela ou outros atos próprios da administração pública federal enquanto órgão executor; e tampouco iniciar qualquer pactuação com sentido político-administrativo em nome do Iphan. Buscou-se, por fim, a verificação dos dados levantados com vistas a aprimorar a proposta de Plano de Preservação. 


\section{ID_PESQUISAS}

\section{CONCLUSÃO}

Como conclusão da experiência relatada, verificamos que o método de inventário SICG aplicado ao território com fins de geração de conhecimento sobre paisagem mostrou-se suficiente, desde que somado a instrumental próprio para o aprofundamento das referências culturais dos grupos sociais, como foi, no caso, a utilização do roteiro de questões aqui apresentado.

O relatório sobre a legislação incidente na porção territorial foi, por sua vez, indispensável para o aprofundamento do conhecimento sobre o território e para a formulação de propostas de preservação do patrimônio.

Portanto, do ponto de vista técnico-metodológico, consideramos que os objetivos foram atingidos com base no instrumental existente no Iphan. Cabe a observação de que uma investigação de tal complexidade e abrangendo variados temas de levantamento e pesquisa pressupõe a formação de uma equipe interdisciplinar capacitada para o trabalho.

Além disso, foi importante no âmbito do IPHAN, o fortalecimento do trabalho transversal e a aproximação entre as diferentes unidades administrativas, cada qual com suas rotinas e papéis diferenciados de atuação.

No momento atual, cabe ao IPHAN dar continuidade à articulação política e técnica necessária para a efetivação das ações de preservação, seguindo os passos de instrução do processo de chancela propriamente dito, com base nos subsídios obtidos. Isso inclui fazer-se presente no território; promover reuniões com os atores locais; buscar a pactuação entre os parceiros; e decidir, em processo continuado de construção de política pública, sobre o Plano de Gestão. 
ID_PESQUISAS

\section{REFERÊNCIAS BIBLIOGRÁFICAS}

Acervo IPHAN (2009). "Inventário do Patrimônio Cultural das Localidades da Calha do Rio São Francisco". Empresas contratadas: Fare Arquitetura e Demacamp.

Acervo IPHAN/ Superintendência do IPHAN em Sergipe (2013). "Levantamento Preliminar do Inventário Nacional de Referências Culturais (INRC) da região ribeirinha sergipana do Baixo São Francisco". Empresa contratada: Memória Arquitetura.

Acervo IPHAN (2014). "Inventário de conhecimento do Patrimônio Cultural da Foz do Rio São Francisco, nos municípios de Brejo Grande, Pacatuba e Piaçabuçu - SE e AL". Empresa contratada: Memória Arquitetura. 